\title{
UNMANNED AERIAL VEHICLE (UAV) SURVEY-ASSISTED 3D MANGROVE TREE MODELING
}

\author{
Gerard A. Domingo ${ }^{1}$, Alexis Richard C. Claridades ${ }^{1,2, *}$, Mark Edwin A. Tupas ${ }^{1,2}$ \\ ${ }^{1}$ IAMBlueCECAM Program Project 9: WebGIS for Mapping, Supporting Decision-making, and Promoting Ecological Services of \\ Blue Carbon Ecosystems, University of the Philippines, Diliman, Quezon City 1101 \\ ${ }^{2}$ Department of Geodetic Engineering, University of the Philippines, Diliman \\ *acclaridades@up.edu.ph
}

KEY WORDS: Mangroves, 3D Visualization, 3D Modeling, Unmanned Aerial Vehicle, Assistive Modeling

\begin{abstract}
:
3D visualization is a tool that supports geospatial analysis through the application of scientific information. It enhances the quality of standard photography and can be used in many applications. Through this study, a 3D mangrove tree model is generated, as assisted by a tree crown derived from UAV images. The researchers explored different platforms namely: MeshLab, SketchUp (with 3D Tree Maker extension), and Clara.io, to come up with a more realistic three-dimensional (3D) model of a mangrove tree. From an Unmanned Aerial Vehicle (UAV) derived Digital Surface Model (DSM), an isolated tree crown was selected which was then used as an assisting tool in creating the final 3D mangrove tree model. A default tree object was modified according to the characteristics as described by the DSM. Additional branches and leaves were added to the existing tree object, and its shape was modified to conform to the tree crown. The resulting model may be used to more accurately depict objects in the area to be visualized, however an automation procedure is recommended for an easier and more effective generation of multiple tree models expected in an area.
\end{abstract}

\section{INTRODUCTION}

\subsection{Background of the Study}

$3 \mathrm{D}$ visualization is a tool for more effective decision-making processes. It allows better communication between policymakers and the public (Lange, 2005). Through geovisualization, policymakers can make a virtual replica of the current situation and present it to the public. (Laurini, 2017, www.civilfx.com, 2016). 3D visualization enhances and improves visual communication. Majority of the people can perceive and understand better if objects and scenes are rendered realistically. Compared to 2D maps and still graphics, $3 \mathrm{D}$ visualizations can portray more realistic objects and enhances how the user can comprehend patterns, relations, trends, and critical points (Laurini, 2017). For example, buildings would appear as rectangles in a 2D map but would appear as they are in a 3D visualization. 3D modeling is the processes of creating a three-dimensional virtual representation of an object in various fields. It is sometimes integrated with spatial analysis through geographic information system (GIS). Specifically, this type of modeling is called 3D spatial modeling. One of its distinct characteristics is that objects are georeferenced (Turner, 1989).

Through the fast-improving technology, comes various techniques in generating 3D scenes for visualization as well as individual 3D modes incorporated in each scene. This study integrates two free desktop software programs- MeshLab and SketchUp Make with 3D Tree Maker extension, and an online application, Clara.io, to generate a 3D model of a mangrove tree, following its crown derived from a drone survey. In this way, a mangrove tree can be well represented for visualization purposes since the model better replicates the shape and form of the actual tree compared to a built-in model from a specific software. However, the researchers used a tree model from 3D Tree Maker as the base model for the researchers found it more time and cost efficient than to create a model from scratch.
Furthermore, this study will be a good basis for visualization of an entire mangrove forest, once extended.

\subsection{Objectives}

Through this study, the researchers aim to create a 3D model of a mangrove tree aided by a crown derived from UAV images. Specifically, this paper intends to provide a step-by-step procedure in generating a more effective $3 \mathrm{D}$ single mangrove tree model. This can be used as a basis for visualization of an entire mangrove forest that better represent the actual scenario.

\subsection{Limitations}

This study is a preliminary study in modeling an entire mangrove forest, so it is limited to model a single tree only. While doing the model, the researchers used HP Pavilion 14v015tx Notebook PC with the following specifications:

\begin{tabular}{|l|l|}
\hline \multicolumn{1}{|c|}{ Aspect } & \multicolumn{1}{|c|}{ Specification } \\
\hline Microprocessor & $\begin{array}{l}\text { 1.7 GHz Intel Core i5-4210U with Intel } \\
\text { HD Graphics 4400 }\end{array}$ \\
\hline Installed RAM & $\begin{array}{l}\text { 4 GB 1600 MHz DDR3L SDRAM (1 x } \\
\text { 4GB) }\end{array}$ \\
\hline $\begin{array}{l}\text { Video } \\
\text { Graphics }\end{array}$ & $\begin{array}{l}\text { NVIDIA GeForce 830M (2 GB), } \\
\text { Dedicated }\end{array}$ \\
\hline Hard Drive & 500 GB 5400 rpm SATA \\
\hline $\begin{array}{l}\text { Operating } \\
\text { System }\end{array}$ & $\begin{array}{l}\text { Upgraded from Windows 8.1 to } \\
\text { Windows 10 Home Single Language }\end{array}$ \\
\hline Display & $\begin{array}{l}\text { 14" diagonal HD BrightView WLED- } \\
\text { backlit (1366 x 768) }\end{array}$ \\
\hline
\end{tabular}

Table 1. Specifications of workstation used

With this computer, the 3D Tree Maker extension of SketchUp Make does not work properly. No changes can be detected when settings in the branches, leaves and other tree elements were altered. However, the researchers used one built-in model from this extension as a base model. Also, since Clara.io is an online application, the processing time is greatly affected by the 
speed of the internet. Furthermore, there was no assessment performed to evaluate the effectiveness and usability of the model.

\section{REVIEW OF RELATED LITERATURE}

\subsection{Landscape Visualization}

Landscape visualization is the application of different visualization methods in modeling various land forms on the earth's surface (Schroth, 2010). Deussen et al. (1998) created a system that can support landscape visualizations. This system reduces the memory requirement by using representative objects instead of group of plants. However, this results to simple but unrealistic and physically incorrect models. It also cannot incorporate the sun and its light thus portraying no shadows. The only remedy was to add shadow maps (Clasen and Hege, 2005.).

\subsection{Canopy Modeling}

In 1995, Ramsey and Jensen modeled mangrove canopy reflectance using a light interaction model and an optimization technique. In their study, they obtained the canopy reflectance spectra of the different mangrove species such as black (Avicennia), white (Laguncularia), and red (Rhizophora) mangroves from an airborne high-resolution data. Then, canopy characteristics were predicted using the light interaction model with an optimization routine and the derived reflectance spectra. In 1996, the same researchers were able to relate the acquired reflectance spectra into site-specific data. Their further study showed that by using normalized difference vegetation index (NDVI) the $84 \%$ of the leaf area index (LAI) variance was justified. They were also able to prove that the canopy LAI was positively related to canopy height. After achieving interesting results, yet, Ramsey and Jensen did not extend their methodologies into three-dimensional modeling in this paper.

\subsection{D Mangrove Mapping}

Using object-based image analysis techniques based on UAV hyperspectral images obtained from UHD 185, a commercial hyperspectral imaging sensor, attached on a UAV platform, Cao et al. (2018) were able to perform mangrove classification on Qi'ao Island. Their methodology is shown in Figure 1.

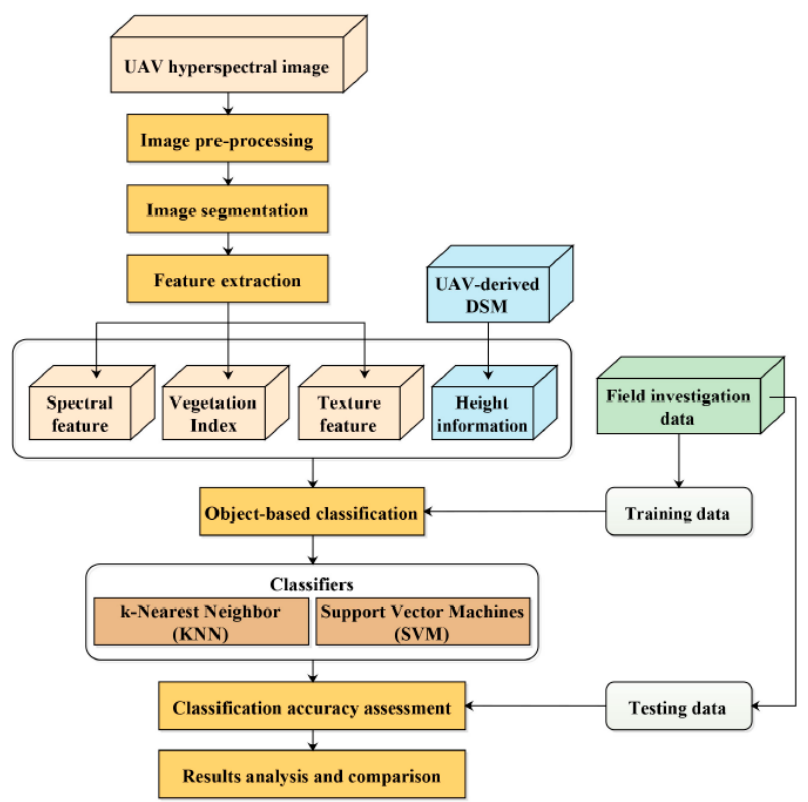

Figure 1. Methodology by Cao, et al. (2018) for object-based mangrove species classification from UAV hyperspectral image

The UAV hyperspectral image and the UAV-derived DSM were used to generate objects. Using the same set of data, they extracted height information, vegetation indices, textural and special features. Then the classification and regression tree (CART) method and the correlation-based feature selection (CFS) algorithm were utilized for band selection and feature reduction respectively. Finally, they were able to classify these objects into different mangrove species and other land covers based on their spectral and spatial characteristic differences.

In this paper, the researchers also aim to use an object-based image analysis technique derived from UAV images, but would focus on generating a 3D model of a mangrove tree instead of image classification.

\subsection{D Modeling}

In a previous research, the researchers generated visualization products using 4 different platforms such as Google Earth, ArcScene, Virtual Terrain Project, and Terragen. Outputs from each platform were compared in terms of effectivity and effectiveness using a perception survey. The results show that people with different knowledge and background tend to prefer different platforms depending on their field of expertise (Domingo, et al., 2017).

However, one of the limitations of the researchers was that they only used built-in 3D object models available within the four platforms mentioned. Also, one of the notable recommendations of that study was to incorporate 3D models and orthophotos from UAV images to improve the visualization products and to have a more virtually realistic and accurate model.

\section{SELECTION AND ISOLATION OF TREE CROWN}

Figure 2 shows the step-by-step methodology of this study.

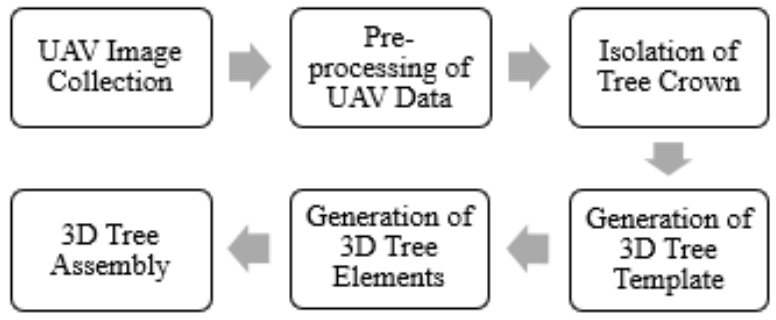

Figure 2. General methodology of this study

From a previously study, the researchers were able to capture UAV images of a mangrove forest in Banate Bay, Iloilo using DJI Phantom 4 Professional. Since UAV survey is an in-situ method, the researchers needed to be in the area. Through this, they were also able to identify that one of the most common specie of mangrove in that area was Rhizophora.

From the UAV images, the researchers generated 3D model of a mangrove forest processed through AgiSoft, as seen in Figure 3 . Then, they look for a secluded tree crown that can be isolated from the entire model. This tree crown will be used as the subject tree in this study. 
The International Archives of the Photogrammetry, Remote Sensing and Spatial Information Sciences, Volume XLII-4/W9, 2018 International Conference on Geomatics and Geospatial Technology (GGT 2018), 3-5 September 2018, Kuala Lumpur, Malaysia

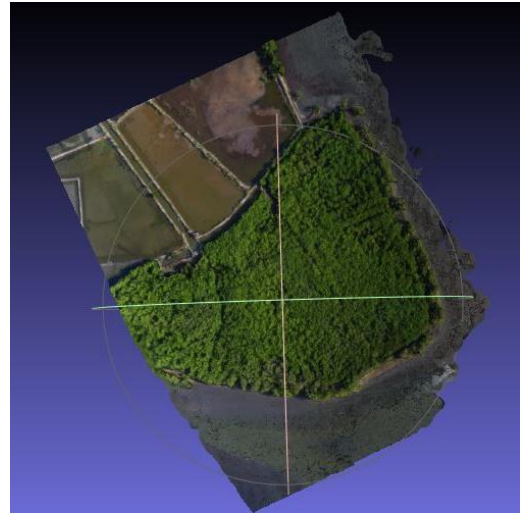

Figure 3. 3D model of a mangrove forest in Banate Bay, Iloilo generated from UAV images

Figure 4 shows that there is a secluded tree crown at the lower right tip of the mangrove forest. Instead of selecting everything else, excluding the subject tree crown, secluded tree crown was selected and use Invert Selection tool to then select areas outside the crown of concern, for deletion. This leaves only the tree crown of concern.

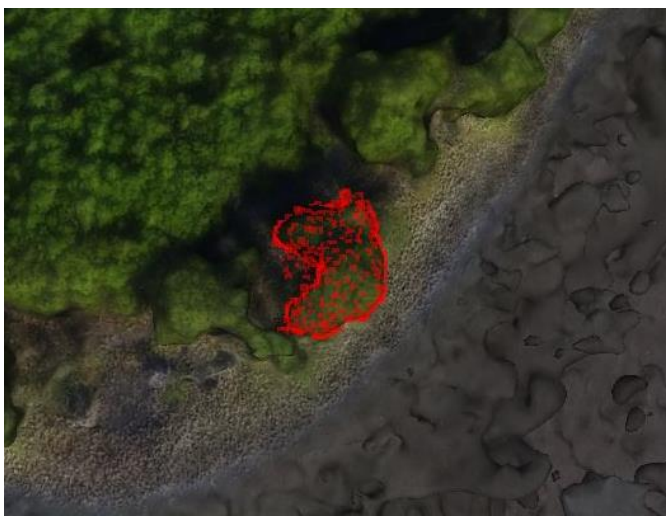

Figure 4. Tree crown selection in MeshLab

The tree crown was exported as Collada (.dae) file, which can be imported into SketchUp. Shown in Figure 5 that not only the tree crown itself was exported but it also contains some parts of the ground. The position of the ground may be used be a reference for the height of the mangrove tree model. Furthermore, it can also be seen that this tree crown is too big for just one tree. It is observed that this isolated tree crown may be consisted of not just one, but multiple mangrove trees.

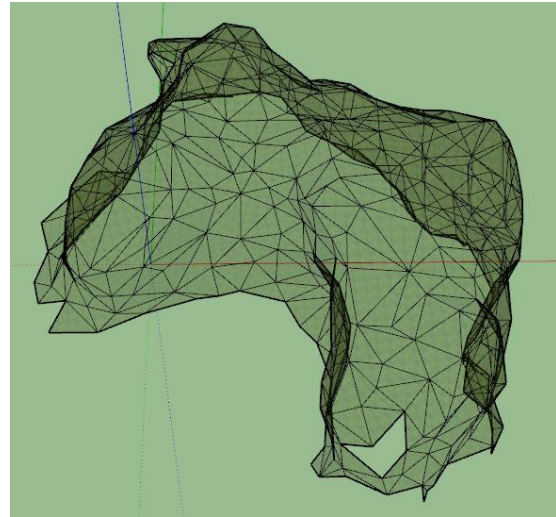

Figure 5. Isolated tree crown as viewed in SketchUp
To validate the observation of the researchers, raw images from the UAV survey were inspected. Figure 6 shows that there are approximately about 4-5 mangrove trees within the isolated tree crown. Thus, the researchers selected only one tree to be modeled.

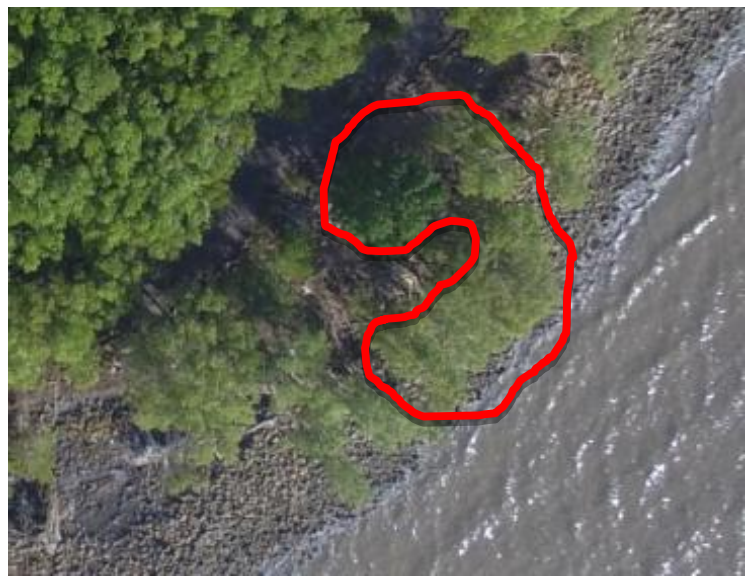

Figure 6. UAV raw image containing the isolated tree crown

\section{GENERATION OF A 3D TREE TEMPLATE AND 3D TREE ELEMENTS}

A 3D tree template was created using the "tree41: Generic Tree 41" of 3D Tree Maker, which has similar characteristics to a mangrove tree. Tree41 was identified to have eye-shaped, shiny green leaves as well as comparable structure of the branches than that of a mangrove tree. However, the roots, which are notable in mangrove trees, were not portrayed as these lie covered by the tree canopy in the DSM.

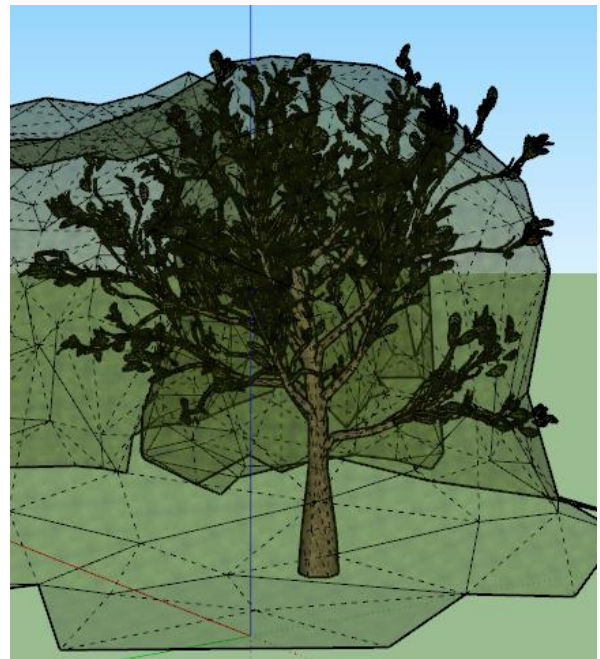

Figure 7. 3D tree model within the tree crown

The tree template was placed within the tree crown model to check if it fits properly. Figure 7 shows that the tree template has a little resemblance to the tree crown and does not fit right. Thus, alterations are still necessary.

Using Clara.io, some branches and leaves were separated from the template. These tree elements were exported as Collada (.dae) files, so that it can be imported back to SketchUp after modification. 


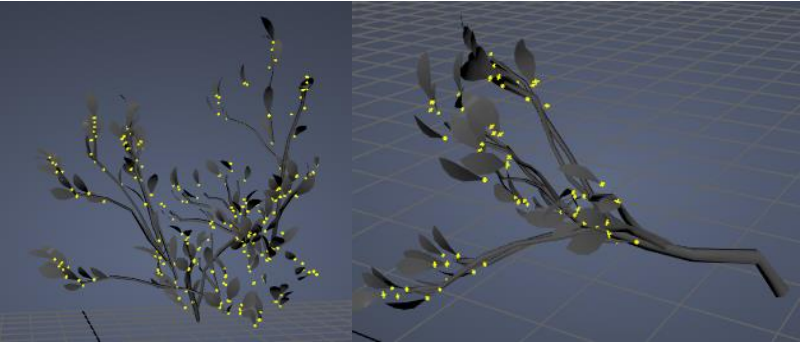

Figure 8. 3D tree elements generated from Clara.io

\section{3D MANGROVE TREE ASSEMBLY}

Now, alterations from the template model can be done to make it a proper fit into the tree crown. 3D tree elements were imported into SketchUp and was applied with proper texture, similar to the tree template.

Before adding the tree elements, the existing tree template was first altered. Excess branches and leaves were deleted while other branches and leaves were resized using the Scale tool. The output is shown in Figure 9.

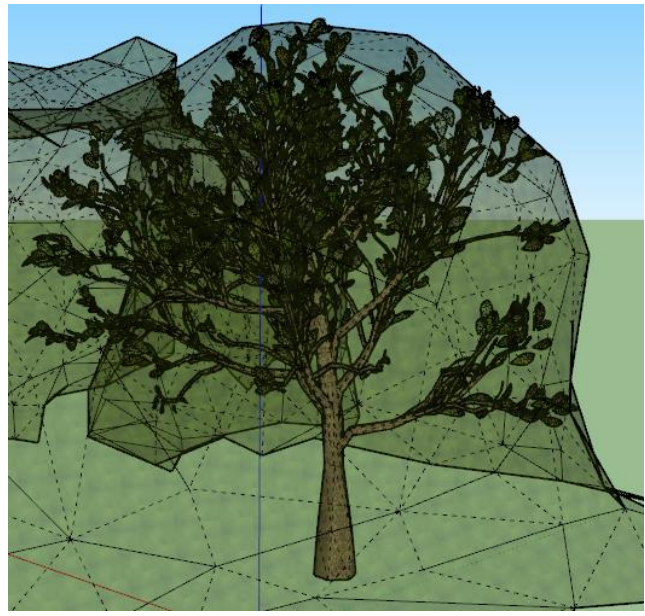

Figure 9. First alteration of the tree template

Lastly, additional branches and leaves were added to achieve a mangrove tree model that fits into the tree crown model. Figure 10 shows the final 3D mangrove tree model. This model conforms better to the tree crown described by the DSM, compared to the default template shown in Figure 7.

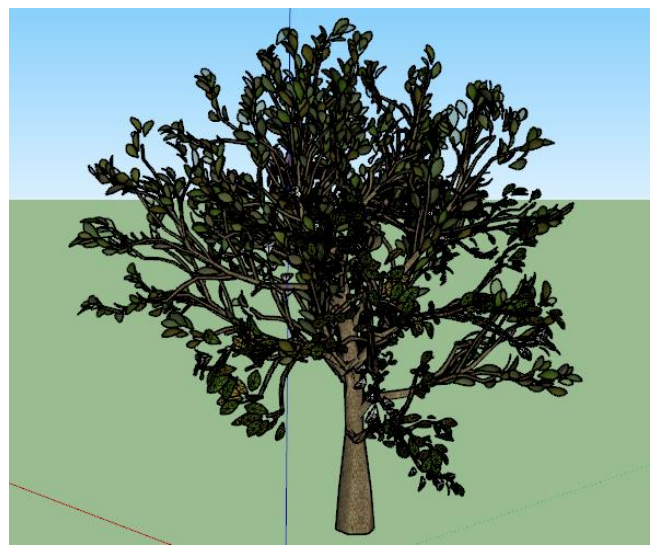

Figure 10. Final 3D mangrove model

\section{CONCLUSIONS AND RECOMMENDATIONS}

\subsection{Conclusions}

This study shows a step-by-step procedure in generating a 3D model of a mangrove tree assisted by a tree crown derived from UAV images. Moreover, the researchers were able to create a more improved 3D mangrove tree model compared to a built-in model generated by a software. The generated model follows the shape of its own crown, as characterized by the DSM generated from the UAV images.

\subsection{Recommendations}

The researchers recommend the following for further studies: First is to use a higher processing computer to better utilize the function of the 3D Tree Maker extension of SketchUp. Secondly, automation of this process would be a great tool to create a model of not just a single mangrove tree but even an entire mangrove forest faster and more efficiently. It is also recommended to explore free and open source applications or platforms for easier automation, and interoperability of the data formats. Finally, it is recommended to conduct a perception survey to assess the effectiveness of the final model as a 3D abstraction of a mangrove tree in digital format.

\section{ACKNOWLEDGEMENTS}

This work is primarily funded by the Department of Science and Technology, Philippine Council for Industry, Energy, and Emerging Technology Research and Development (DOSTPCIEERD) with Project No. 04047, 2018.

The researchers would also like to acknowledge the following people and institutions for their significant contributions and participation to make this research possible. Without them, this study cannot be fulfilled within the given timeframe. Special thanks to Dr. Ariel Blanco, local government of Anilao, Iloilo, especially to Ms. Emee Grace Miatapal, National Mapping and Resource Information Authority, Bureau of Fisheries and Aquatic Resources, and Dr. Rene Rollon of UP Institute of Environmental Science and Meteorology for providing us with necessary information and data for this study

\section{REFERENCES}

Bailey, J.E., Whitmeyer, S.J. and D.G. De Paor., 2012. Introduction: The application of Google Geo Tools to geoscience education and research. The Geological Society of America.

Cao, J., Leng, W., Liu, K., Liu, L., He, Z., and Zhu, Y., 2018. Object-Based Mangrove Species Classification Using Unmanned Aerial Vehicle Hyperspectral Images and Digital Surface Models.

CivilFX, 2016. Top 10 Benefits of 3D Visualization. Retrieved from http://www.civilfx.com/benefits-3darchitecturalvisualization/

Clasen, M. and H. C. Hege, 2005. Realistic Illumination of Vegetation in Real-Time Environments. In Trends in Real-time Visualization and Participation, New Technologies for Landscape Architecture and Environmental Planning, Wichmann Verlag. 
The International Archives of the Photogrammetry, Remote Sensing and Spatial Information Sciences, Volume XLII-4/W9, 2018

International Conference on Geomatics and Geospatial Technology (GGT 2018), 3-5 September 2018, Kuala Lumpur, Malaysia

Domingo, G. A., Mallillin, M. M., Perez, A. M. C., Claridades, A. R. C., and Tamondong, A. M., 2017. 3D Visualization of Mangrove and Aquaculture Conversiom in Banate Bay, Iloilo, Int. Arch. Photogramm. Remote Sens. Spatial Inf. Sci., XLII4/W5, 53-60, https://doi.org/10.5194/isprs-archives-XLII-4W5-53-2017, 2017.

Green, J., 2016. What Is 3D Visualization, Who Does It \& Why Do You Need It? Retrieved from https://www.upwork.com/hiring/design/what-is-3dvisualization -who-does-it-why-do-you-need-it.

Hewlett-Packard, Inc. HP Costumer Support. Retrieved from https://support.hp.com/ph-en/document/c04334480

Lange, E., 2005. Issues and Questions for Research in Communicating with the Public through Visualizations. Proceedings at Anhalt University of Applied Sciences: Trends in Real-time Landscape Visualization and Participation. Retrieved

http://www.masterla.de/conf/pdf/conf2005/11lange_c.pdf.

Laurini, R., 2017. Geographic Knowledge Infrastructure: Applications to Territorial Intelligence and Smart Cities. ISTE Press.

Mei, G., Tipper, J. and N. Xu., 2013. 3D Geological Modeling and Visualization of Rock Masses Based on Google Earth: A Case Study. Cornell University Library. Retrieved from https://arxiv.org/abs/1301.3455.

Ramsey, E.W. and J.R. Jensen., 1995. Modelling Mangrove Canopy Reflectance by Using a Light Interaction Model and an Optimization Technique. In: Wetland and Environmental Applications of GIS, J.G. Lyon, and J. McCarthy, eds., pp. 6181. Boca Raton, FL: Lewis Publishers.

Ramsey, E.W. and J.R. Jensen., 1996. Remote Sensing of Mangrove Wetlands: Relating Canopy Spectra to Site-Specific Data. Photogrammetric Engineering and Remote Sensing 62:939-948

Schroth, O., 2010. From Information to Participation: Interactive Landscape Visualization as a Tool for Collaborative Planning. Bibliografische Information der Deutschen Nationalbibliothek.

Simard M., Rivera-Monroy, V., Mancera-Pineda, J. E., Castañeda-Moya, E., and Twilley, R., 2008. A systematic method for 3D mapping of mangrove forests based on Shuttle Radar Topography Mission elevation data, ICEsat/GLAS waveforms and field data: Application to Ciénaga Grande de Santa Marta, Colombia.

Turner, A.K., 1989. Three-Dimensional Modeling with Geoscientific Information Systems. Kluwer Academic Publishers.

Warren-Kretzschmar, B. and S. Tiedtke. What Role Does Visualization Play in Communication with Citizens? - A Field Study from the Interactive Landscape Plan.

Wisniewski, P.K., Pala, O., Lipford, H.R. and D. Wilson., 2009. Grounding Geovisualization Interface Design: A Study of Interactive Map Use. Spotlight on Works in Progress. Boston, Massachusetts, USA.
Revised August 2018 